\title{
INTERVENCIONES
}

\section{El estudio de la clase trabajadora y las izquierdas: recorridos historiográficos y perspectivas}

\author{
Sergio Grez Toso - Gabriela Águila - Hernán Camarero
}

Los dias 3, 4 y 5 de octubre se realizaron en Buenos Aires las "II Jornadas Internacionales de historia del movimiento obrero y la izquierda" organizadas por la revista Archivos y el CEHTI. El panel de cierre del evento se dedicó a un examen de la evolución, el actual estado y las perspectivas de nuestro campo de estudios, bajo el titulo que preside esta Sección. La mesa estuvo integrada por el Dr. Sergio Grez Toso, profesor e investigador de la Universidad de Chile; la Dra. Gabriela Águila, profesora e investigadora del Conicet y la Universidad Nacional de Rosario, y el Dr. Hernán Camarero, profesor e investigador del Conicet y la Universidad de Buenos Aires y director del CEHTI. A continuación se transcriben las intervenciones, revisadas por sus autores.

\section{La historiografía reciente de la clase trabajadora y las izquierdas en América Latina. Una mirada desde Chile}

\section{Sergio Grez Toso}

Universidad de Chile sergiogreztoso@gmail.com

Abordar la historiografia de las izquierdas y del movimiento obrero latinoamericano es una tarea prácticamente imposible de realizar en breves minutos. Por ello expondré algunas ideas sueltas que pueden 
servir para un debate que nos ayude a encontrar colectivamente algunos elementos de orientación. Tomaré como punto de partida algunos planteamientos formulados hace treinta años por nuestro amigo y colega Ricardo Melgar Bao en la Introducción de su libro El movimiento obrero latinoamericano, quien constataba que hasta ese momento el movimiento obrero del subcontinente había sido historiado a partir de su expresión sindical siguiendo una tradicional perspectiva historiográfica, cuestión que lo llevaba a tomar distancia de dicha perspectiva en la manera de reconstruir el quehacer sindical, poniendo también atención a otras formas de resistencia obrera. Hacia entonces, sostuvo, ya habia comenzado a producirse en varios países de la región un distanciamiento de la historiografia relativa al movimiento obrero respecto de "los límites economicistas con los que se han solido analizar y correlacionar los procesos de proletarización-pauperización con las formas de protesta obrera, así como los estrechos ámbitos del sindicalismo y del vanguardismo proletarios que durante media centuria monopolizaron en este campo las investigaciones en ciencias sociales" (El movimiento obrero latinoamericano, Madrid, Alianza Editorial, 1988, tomo I, p. 16).

La auscultación de otros planos de la existencia de la clase obrera -destacaba este historiador- aún revestía en América Latina el "carácter de monografias locales y temáticas segmentadas" que abrian nuevas perspectivas de estudio.

Debemos preguntarnos: ¿qué estaba ocurriendo en la década de los 80 en la historiografia latinoamericana consagrada al estudio de las izquierdas y de los trabajadores?

Aunque es dificil dar una respuesta que englobe a todas las comunidades historiográficas del subcontinente, me parece que es posible detectar ciertos rasgos comunes en varios casos nacionales. De manera apretada destacaria los siguientes:

Los fracasos de las experiencias populistas, nacional desarrollistas y revolucionarias de las décadas de 1960 y 1970 en países como Brasil, Argentina, Uruguay, Bolivia y Chile, junto a las dictaduras que se instauraron en reemplazo de los regímenes democráticos, además de otros casos de establecimiento de sangrientas dictaduras y hegemonía reaccionaria en América Central y el Caribe, produjeron una profunda conmoción entre los historiadores de izquierda, cultores por excelencia de estos temas.

A partir de 1968 se sumaron las crisis de los socialismos reales, que también cuestionaron una serie de supuestos ideológicos, en particular cierto esencialismo atribuido a la clase obrera y a sus autodesignadas vanguardias politicas.

Esto, en medio de debates disciplinarios surgidos en los principales centros de producción de insumos teóricos de Europa -sobre todo en 
Francia e Inglaterra- que reforzaron el cuestionamiento de algunos paradigmas epistemológicos, en particular un estructuralismo que, aplicado con particular fervor, llevaba a algunos cultores de la disciplina a entender la historia social como exposiciones caracterizadas por una "larga duración" de carácter determinista en el que las pasiones humanas y los actos conscientes de las personas - por ende la política- no cuentan o cuentan muy poco. En comunidades historiográficas como la chilena -censurada, vigilada, perseguida, encarcelada y con una parte de sus integrantes exiliados- estos hechos provocaron reacciones contradictorias, la mayor parte, a la larga, positivas.

De manera muy resumida podría decirse que, en nuestro caso, desde fines de los años 80 del siglo pasado, la historiografia social -caracterizada hasta la década anterior por el estructuralismo proveniente de la Escuela de los Anales y del marxismo estructuralista- dio paso a un saludable retorno del acontecimiento (estudio de huelgas, movilizaciones sociales, masacres, entre otros). Paralelamente, los historiadores sociales descubrieron nuevos sujetos de estudio: peones, artesanos, campesinos, mujeres populares; ya no solo el proletariado minero y fabril tradicional de la historiografia marxista clásica. También se redescubrieron o auscultaron otros sujetos políticos actuando en el movimiento obrero: anarquistas, demócratas, "nueva izquierda" de los 60 y 70 o incluso más allá de la izquierda (católicos sociales), que se sumaron a los objetos de estudio clásicos como socialistas y comunistas. Posteriormente se añadieron los estudios que se han propuesto una combinación del enfoque más tradicional de la historia social y política con la perspectiva de género en el análisis de la historia del movimiento obrero y de las izquierdas. Estos cambios en la dirección de las miradas llevaron a la historiografia a enfocarse menos en ciertos fenómenos que en algunas versiones historiográficas aparecian revestidos de un fuerte a priori ideológico, como el concepto de "conciencia de clase", para centrarse preferentemente en fenómenos como las "identidades populares", menos ancladas en los discursos políticos de los partidos "de clase" y con mayor énfasis en las experiencias de la condición popular.

No obstante estos saludables quiebres, la historiografia social chilena incurrió durante un cuarto de siglo en un marcado desprecio por la historia del movimiento obrero y de las izquierdas. Importantes referentes de la disciplina abandonaron el estudio de la clase obrera, el movimiento obrero y sus expresiones politicas (los partidos y corrientes de izquierda) por considerarlo superado, innecesario y hasta contraproducente debido a las justas críticas que cargaba sobre sus espaldas la historiografia marxista clásica (se acusaba su rigidez, dogmatismo, vanguardismo, esencialismo, determinismo y concepción lineal de la historia que desembocaba inevitablemente en una visión teleológica 
asociada a la "misión histórica del proletariado"). Aunque no es posible extenderse sobre este asunto, hay que consignar que, de seguro, pesó en este desprecio por la historia del movimiento de trabajadores -al igual que en muchas partes del mundo- la crisis del trabajo y de las organizaciones sindicales, del mismo modo que la "caída de los muros".

Como bien lo explicó Juan Suriano refiriéndose a la Argentina -lo mismo ocurrió en Chile y otros países- la aplicación de las políticas neoliberales no se agotó en el fenómeno de la exclusión social, también dejó su huella en el ámbito académico. El crecimiento del desempleo y del empleo precario hizo que el trabajo pareciera perder el lugar central que había ocupado durante décadas en la experiencia vital de las personas, lo que redundó en un sostenido deslizamiento de los estudios sobre la historia de los trabajadores hacia los márgenes de la disciplina (J. Suriano, "Los dilemas actuales de la historia de los trabajadores", en Jorge Gelman, La historia económica argentina en la encrucijada. Balance y perspectivas, Buenos Aires, Prometeo, 2006). En una suerte de movimiento pendular de compensación, la "nueva historia social" chilena se inclinó aplastantemente por el estudio de lo premoderno, espontáneo, identitario, irracional y sensual, lo "puramente social", las rebeldías primitivas y las actividades de subsistencia popular. ¡Sin exagerar, puede decirse que hacia fines de los 90 en Chile no había más que media docena de historiadores centrados en el estudio del movimiento obrero! El rechazo a la "interpretación alucinantemente política" de los procesos históricos planteado por Gabriel Salazar ("Crisis en la altura, transición en la profundidad: la época de Balmaceda y el movimiento popular", en Luis Ortega [ed.], La guerra civil de 1891. Cien años hoy. Santiago, Departamento de Historia - Universidad de Santiago de Chile, pág. 172), llevó a numerosos historiadores sociales y a sus discípulos a postular, si no en teoria, al menos en los hechos, una historia de "los de abajo" vaciada de su acción política.

Afortunadamente, desde hace poco más de una década se empezó a revertir este oscuro panorama de la historiografia del movimiento obrero y de las izquierdas en Chile. Coincidentemente con la repolitización de la sociedad chilena que se insinuó hacia el 2006 y se manifestó con mayor fuerza a partir del 2011, se fue despertando un mayor interés por los trabajos de nueva historia politica y, por ende, del movimiento obrero y de las izquierdas. ¡La lucha casi solitaria que habiamos dado un minúsculo puñado de refractarios a las tendencias de moda empezó a dar resultados! (Sergio Grez Toso, "Escribir la historia de los sectores populares. ¿Con o sin la política incluida? A propósito de dos miradas a la historia social [Chile, siglo XIX]", en Politica, vol. 44, Santiago, otoño de 2005). Nuevas camadas de historiadores e historiadoras jóvenes se interesaron por estos, hasta poco antes, desdeñados temas, agregan- 
do nuevas dimensiones (como las culturales y de género), que se han sumado a perspectivas más tradicionales. Su numerosa presencia en estas Jornadas es prueba de ello.

Tengo la intuición de que en otros lugares de América Latina se están suscitando procesos parecidos. Fruto de esta nueva realidad, podemos constatar con satisfacción que en nuestros países hoy se estudia prácticamente todo lo que hasta ahora es posible imaginar sobre las izquierdas y el movimiento obrero. Pareciera ser que en casi todas partes ha retrocedido la historia militante (apologética y hagiográfica), al igual que la mirada sociológica, con sus tendencias a ignorar las experiencias concretas de los trabajadores. Basta una ojeada a los índices de algunas revistas, libros y reuniones científicas de nuestra área para constatar que en la actualidad son cada vez más abundantes los estudios sobre las organizaciones sindicales, mutualistas, cooperativistas, culturales, deportivas, barriales, etarias y de género de la clase obrera y de los trabajadores; sus liderazgos, composición social, reivindicaciones y estrategias; sus vínculos con los partidos políticos, las iglesias, la masoneria y el Estado; los conglomerados internacionales que agrupan a estas instituciones de los trabajadores; las relaciones entre clase, género, etnia y nación; los movimientos sociales y de protesta: petitorios, huelgas, ocupaciones de fábricas y lugares de trabajo; las relaciones del movimiento obrero con otros movimientos como el campesino, indigena y estudiantil; la violencia social y politica en las relaciones entre trabajadores, patrones y el Estado: represión, golpes de Estado, asonadas y levantamientos populares, guerrilla, contrainsurgencia, etc.; la actitud y respuesta de los trabajadores frente a las estrategias de contención social y cooptación implementadas por las clases dirigentes (como las leyes sociales, los mecanismos de conciliación y arbitraje y el paternalismo industrial); el sindicalismo latinoamericano observado globalmente y en perspectiva comparativa (aunque en este plano hay que reconocer que los aportes más destacados en las últimas décadas los hicieron algunos sociólogos -como Torcuato Di Tella y Francisco Zapata- que incursionaron en el terreno mixto de la historia y la sociologia). Igualmente, se estudian las izquierdas en todas sus dimensiones: sus programas, postulados ideológicos y formas de organización; sus imaginarios y prácticas culturales; su prensa y estrategias comunicacionales; sus postulados éticos y morales; sus estrategias politicas, métodos de lucha, pugnas, disidencias y vínculos internacionales. También se trabaja sobre la historia intelectual de las izquierdas.

Constatamos, pues, que desde el diagnóstico que hiciera Ricardo Melgar Bao hace treinta años, ha pasado mucha agua bajo los puentes de la historiografia latinoamericana sobre estas cuestiones.

Entre los asuntos ya señalados, destaco por mi cercanía temática -no 
necesariamente por una supuesta mayor importancia- la revitalización de los estudios sobre violencia politica, a la vez que sobre el anarquismo y el comunismo, especialmente en Argentina, Brasil, Chile, Uruguay, Colombia, Perú, Brasil, México y Guatemala, tanto en sus facetas más clásicas (ideologia, estrategias, organización, acción política, etc.) como en sus dimensiones culturales, además de disidencias y estructuras internacionales.

El internacionalismo de ambas corrientes de redención social ha suscitado el interés de especialistas de otros continentes que han reforzado el conocimiento sobre anarquismo y comunismo latinoamericanos. Destacan especialmente los grandes aportes documentales e historiográficos sobre el comunismo y sus redes realizados por los investigadores rusos Lazar y Víctor Jeifets, Andrey Schelchkov y, muy especialmente, por Olga Ulianova, fallecida en Chile a fines de 2016.

Existe en estas áreas una incipiente y prometedora tendencia a la colaboración, la constitución de redes formales e informales de investigadores y al comparatismo entre casos nacionales, lo que se ha traducido en los últimos años en iniciativas tales como: la Primera Reunión Internacional Historia de las Izquierdas en América Latina, realizada en Morelia, México, a fines de noviembre de 2007, a través de la naciente Red Iberoamericana para el estudio de las izquierdas en América Latina, cuyo centro en esa ocasión fue el tema de la violencia en México y en Latinoamérica; el Seminario Internacional sobre cultura y política del anarquismo en España e Iberoamérica, que tuvo lugar en El Colegio de México en marzo de 2011; el Seminario Internacional sobre Historia de la Violencia con sus cuatro versiones en Santiago de Chile (2012), Córdoba (2014), La Paz (2016) y Barranquilla (2018); el Seminario Internacional El comunismo y su impacto en América Latina y el Caribe, celebrado en Santiago de Chile en agosto de 2016; el I Congreso Internacional de Investigadores(as) sobre el anarquismo, organizado por el CeDInCI y la Universidad de San Martín, Buenos Aires, en octubre de 2016; las Jornadas sobre Historia de la Izquierda y el Movimiento Obrero organizadas en Buenos Aires por el Centro de Estudios Históricos de los Trabajadores y las Izquierdas (CETHI) en 2015 y 2018; varios congresos y jornadas realizados en 2017 con motivo del centenario de la Revolución Rusa en Moscú, San Petersburgo, París, Rosario, Buenos Aires y otros lugares, en los que historiadores de nuestros países abordaron los vínculos y repercusiones de este acontecimiento en América Latina; el afianzamiento de revistas como la argentina Archivos de Historia del movimiento obrero y la izquierda y la chilena Izquierdas (recientemente vinculada a la Universidad Estatal de San Petersburgo, Rusia), en cuyas páginas se da amplia cabida a estudios internacionales sobre estos temas.

Con todo, la lozanía, vigor y variedad que están cobrando los estu- 
dios referidos al movimiento obrero y las izquierdas latinoamericanas nos plantean algunos problemas que será necesario resolver para poder avanzar con mayor profundidad en las direcciones ya señaladas y en otras que no tardarán en surgir.

Quiero llamar la atención sobre uno de estos problemas.

Al igual que en otras áreas de la historiografia en otros continentes, nuestro campo de especialización sufre -a medida que crece y diversifica su producción- de un fenómeno de creciente fragmentación o atomización. Cada vez más nos vamos formando como especialistas en determinados temas, de modo que tendemos a dialogar solo con pares ultra especializados en los mismos temas. Los especialistas en anarquismo solo dialogan con otros especialistas en anarquismo, los investigadores del comunismo hacen lo mismo con otros colegas, los del sindicalismo con los que estudian el sindicalismo, y así sucesivamente. Solo excepcionalmente se realizan obras generales de sintesis.

Este fenómeno se acentúa aún más fuera del marco del Estado nación: no abundan las historias generales sobre el movimiento obrero ni sobre las izquierdas latinoamericanas. Paradójicamente ello ocurre cuando la acumulación de conocimientos resultantes de centenares de trabajos monográficos sobre nuestros campos comunes ha crecido de manera exponencial en las últimas décadas. Cada vez nos alejamos más del ideal renacentista del humanismo global y nos acercamos más al especialista de un micro campo que pretendemos dominar con precisión quirúrgica. Tendemos a convertirnos en tecnócratas de la historiografia. De seguir en esta dinámica, corremos el riesgo de que sea una triste realidad aquello que sentenciaba Einstein: "mientras más sabemos, menos entendemos".

No se trata de buscar culpas ni soluciones personales. Las grandes obras de sintesis rara vez pueden ser individuales, generalmente son el resultado de trabajos colectivos. Las condiciones de trabajo de nuestras comunidades historiográficas no se prestan para ello. Vivimos en sociedades marcadas por la competencia que han profundizado nuestro individualismo. En la mayoría de los países latinoamericanos las condiciones del mercado de trabajo universitario y de adjudicación de recursos para la investigación histórica tienden a acentuar el trabajo individual y la competencia entre investigadores. Los laboratorios o instancias de colaboración permanente son poco frecuentes. Por ello escasean o no existen proyectos comunes de largo alcance que orienten o al menos intenten dar un sentido general a los esfuerzos desperdigados de investigadores y de pequeños colectivos de trabajo. Nuestras obras se asemejan más a la producción "anárquica" propia del capitalismo liberal que a la de una economía comunitaria.

Ciertamente, no preconizamos una producción historiográfica en base 
a una "planificación centralizada", apuntamos más bien a la necesidad de promover iniciativas que, comenzando por el conocimiento mutuo, permitan articular agendas de trabajo con vasos comunicantes en la perspectiva de proyectos conjuntos de larga duración. Instancias como esta podrian permitirnos avanzar en dicha dirección.

$* * *$

\title{
A propósito de los estudios sobre las izquierdas en la historia reciente argentina
}

\author{
Gabriela Águila \\ ISHIR/Conicet - Universidad Nacional de Rosario \\ gbaguila@gmail.com
}

El objetivo de esta presentación en el marco de un panel centrado en los abordajes sobre la clase obrera y las izquierdas, es plantear un conjunto de reflexiones en torno a ese objeto de estudio en el campo de la historia reciente argentina. Para empezar, me parece necesario situar algunas cuestiones respecto de ese ámbito de indagación y, en primer lugar, hacer una breve referencia al problema de la periodización consignando que el debate sobre los limites temporales de la historia reciente no tiene la misma vitalidad que hace algunos años. Por una economía de tiempo y de argumentación solo diré que hay un consenso bastante instalado sobre el punto de inicio, o sobre los límites temporales "hacia atrás", en tanto el grueso de los trabajos que se inscriben en aquel campo de estudios se ubican en la segunda mitad del siglo XX, en el momento abierto por el derrocamiento del peronismo en 1955. En muchos sentidos, la historia reciente argentina es una historia del período posperonista o, mejor, posperonismo "clásico" (1945-1955).

En segundo lugar, es sabido que la historia reciente argentina se configuró como campo de indagación académica a partir de los años 2000, si bien algunas de sus bases y presupuestos se delinearon en los 90. Ese nuevo campo de estudios se constituyó sobre algunos vacíos innegables, al menos en aquella coyuntura de fines de los años 90 y principios de la década siguiente. Por un lado, respecto del estudio mismo de las últimas décadas de la historia nacional: para quienes se interesaban por aquel periodo resultaba evidente la ausencia de estudios sobre el pasado reciente en la historiografia argentina, como momento 
histórico susceptible de ser analizado según las claves disciplinares de la historia. Son bien conocidas las resistencias de la historiografia y/o de los historiadores/as que hegemonizaron la disciplina desde mediados de los 80 y hasta los primeros años 2000 para abordar ese tramo del pasado con argumentos tales como que se trataba de un pasado "no cerrado", imposibilitando el distanciamiento del historiador de su objeto de estudio, porque no era historia sino "política" y en tal sentido convocaba a posicionamientos políticos de quienes la abordaran, porque se trataba de "historia militante" contraria a la "historia profesional", por solo mencionar algunos tópicos muy reiterados.

Por otro lado, tampoco podía negarse la escasez o incluso la ausencia de estudios sobre ciertos fenómenos o procesos acaecidos en ese tramo del pasado, cuyo tratamiento se veía en gran parte obstaculizado por aquellas resistencias del campo académico, si bien se contaba con análisis provenientes de otras disciplinas como la sociología o la ciencia política. Los vacíos de conocimiento sobre el pasado reciente eran muchos, si bien los que convocaban la mayor atención de los estudiosos eran dos: 1) la conflictividad social y política que habia recorrido la segunda mitad del siglo XX, y en particular los años 60 y 70 y, más específicamente, la violencia insurgente y la lucha armada desplegada por organizaciones politico-militares; y 2) la última dictadura militar, vinculada centralmente con el ejercicio de la represión y las violaciones a los derechos humanos y sus correlatos en el presente. Se trataba de temas que interesaban no solo a una nueva generación de historiadores e historiadoras que se ocuparian de indagarlos, sino que su relevancia y presencia pública se amplificaron notablemente para comienzos del nuevo siglo, en parte como resultado de la crisis de 2001. Se trataba, en resumen, de lo que en uno de los paneles de estas Jornadas Hernán Camarero definía como el "balance sobre los 70", el gran nudo problemático de la historiografia del siglo XX argentino.

Con todo y las resistencias en el ámbito disciplinar de la historia, es un hecho que los estudios sobre el pasado reciente se desarrollaron con una enorme potencia en la última década y media. Las dos cuestiones que antes mencionamos concentraron el grueso de los esfuerzos del vasto conjunto de académicos y académicas que se involucraron en la construcción del campo, sin dejar de mencionar que se trata de los dos nudos problemáticos centrales pero no los únicos, y que por añadidura la producción sobre esas temáticas exhibe desbalances importantes que interesa explicitar aquí.

Uno de ellos es la existencia de una multiplicidad de estudios sobre las organizaciones político-militares frente a otras expresiones del proceso de conflictividad social y política que atravesó los años 60 y 70 . Ello exhibe un panorama de conocimiento desigual, donde puede decirse que 
sabemos más de cualquiera de los numerosos grupos armados provenientes de la izquierda marxista y peronista que actuaron en aquellos años que de la burocracia sindical que dirigió al movimiento obrero en la segunda mitad del siglo XX. A la vez, y para seguir con los desbalances, todavia hoy el principal texto sobre Montoneros es el libro de Richard Gillespie escrito en los años 80, Montoneros. Soldados de Perón, y la bibliografia disponible sobre las organizaciones político-militares está en gran parte nutrida por textos de corte testimonial, más que por trabajos de investigación histórica. De otro lado, ha sido innegable el crecimiento de los estudios sobre la última dictadura, muy vinculados en particular desde los 2000 a la centralidad de la memoria como campo de estudios y reflexión. Pero incluso sin dejar de señalar que la memoria fue principal vía de entrada a la indagación historiográfica sobre el régimen militar, sin la cual probablemente el estudio del periodo hubiera resultado más tardío aún, la producción de conocimiento histórico se abrió paso con más lentitud y dificultades que la narrativa memorialística.

\section{II}

La historia obrera o los estudios sobre los trabajadores y el mundo del trabajo en el periodo posterior a 1955 pueden perfectamente analizarse en forma autónoma de estos desarrollos y por fuera (o relativamente) del campo de la historia reciente. Solo menciono, y muy brevemente porque no será objeto de mi reflexión, que también la clase obrera y los trabajadores fueron relegados como objeto de estudio y colocados en los márgenes de la historia "profesional", en particular aquellos que se ocupaban del período posperonista, más o menos abiertamente cuestionados por su carácter "militante" y deslegitimados en el curso de los años 90.

En ese contexto historiográfico y epocalmente hostil, la historia de los trabajadores y la clase obrera de la segunda mitad del siglo XX pareció desaparecer como campo de estudios, solapándose en análisis desiguales en torno a procesos de corte regional o local, en indagaciones sobre diversas vertientes de la izquierda y/o en el estudio de las décadas del 60 y 70 , en el período que luego se denominaria "historia reciente". La fragmentación entre diversos campos de estudio -no ajena, probablemente, a los derroteros de la historia como disciplina- y el concomitante cambio en el foco del análisis coincidieron con aquella pérdida de centralidad y contribuyeron a la invisibilización de los trabajadores o la clase obrera como objeto de estudio. La revitalización de los estudios sobre la clase obrera y el mundo del trabajo se produjo hacia los 2000, en un proceso paralelo y seguramente imbricado con el desarrollo de la historia del pasado reciente. 
Retomo ahora el eje de esta intervención, volviendo a poner el foco en el campo de la historia reciente, con el objetivo de buscar algunas articulaciones con los estudios sobre las izquierdas. Para dar cuenta de ello voy a recurrir, como recurso argumentativo, a una reseña tan sintética como sesgada de un libro publicado hace muy poco, donde participo como compiladora (G. Águila, L. Luciani, L. Seminara y C. Viano [comps.], La historia reciente en la Argentina. Balances de una historiografia pionera en América Latina, 2018, Buenos Aires: Imago Mundi); no para hacerle publicidad o porque se trate de la única lectura posible sobre aquel campo, sino porque considero que es una muestra bastante acabada de los principales derroteros de la historia reciente en la Argentina.

Entre sus numerosos capítulos, el libro contiene un artículo-balance sobre el movimiento obrero y los trabajadores, que muestra los ritmos y las oscilaciones en las indagaciones sobre la clase obrera y el mundo del trabajo en la segunda mitad del siglo XX y, de otro lado, otro artículo-balance sobre la "experiencia setentista" cuyo objeto central es la lucha armada y las diversas dimensiones de la actuación de las organizaciones político-militares, provenientes del campo marxista y peronista. Sin embargo, no hay nada sobre la izquierda como objeto de estudio específico (agrego que tampoco hay nada sobre la derecha o sobre los partidos políticos, que hubieran merecido sendos capítulos) o, en todo caso, aquella aparece subsumida en otros abordajes centrados en el movimiento obrero y los trabajadores, en el exilio, en los estudios sobre las mujeres y el género, por solo citar algunos.

Esta ausencia de la izquierda como objeto central de un capítulo en un libro que pretende ser un balance de la historia reciente como campo historiográfico puede deberse a la impericia de las compiladoras, aunque tiendo a pensar que es posible otra lectura: que esta ausencia habilita a plantear que en general, en el campo de la historia reciente, la izquierda ha sido mirada no en su especificidad -como sí ha sucedido para la primera mitad del siglo XX-, sino a partir de problemas que reflejan las preocupaciones y lineas de atención predominantes en el campo. Para decirlo más claro: si bien los "recientólogos/as" se han ocupado de estudiar a la izquierda (v.g. cómo no hacer mención al desarrollo de los estudios sobre la "nueva izquierda" o la vertiente de la historia política, intelectual y cultural que la ha examinado en profundidad en los $60 \mathrm{y}$ 70) creo no equivocarme si afirmo que, en líneas generales, su estudio ha sido subsumido o ha quedado solapado por la centralidad de otros objetos más "propios" del campo de la historia reciente. 


\section{III}

Quisiera poner atención en el período que más me convoca, el de la última dictadura y la posdictadura, para dar cuenta de los estudios sobre la izquierda. Para empezar, quiero hacer notar que se trata de uno de los tópicos menos analizados por la historiografia del período y que esto contrasta notablemente con las indagaciones sobre la izquierda en todas sus vertientes y matices que están disponibles para el período previo al golpe de 1976. Aunque podria sostenerse que la historiografia de la dictadura todavía está en construcción, así como constatar que existen un conjunto de trabajos que han abordado las relaciones entre dictadura y partidos políticos, lo cierto es que esos estudios prácticamente no se ocuparon de la izquierda y, adicionalmente, ha predominado una imagen que tiende a invisibilizar su actuación en los años dictatoriales, por efectos de la embestida represiva y legal del régimen militar.

Esta perspectiva no es patrimonio de los estudiosos que se ocupan de los actores burgueses o estatales y/o privilegian miradas "desde arriba", sino que es parte de los estudios realizados también desde la izquierda, por lo que la explicación de tal tendencia historiográfica debe anclarse en la preeminencia de interpretaciones de largo alcance que han enfatizado la cesura que significó el golpe de estado de 1976 respecto de desarrollos previos. El resultado ha sido encapsular las indagaciones sobre la izquierda en sus distintas vertientes en el periodo de mayor conflictividad social y politica (digamos hasta 1975), dando por sentado que la represión estatal desplegada en la segunda mitad de los años 70 borró del mapa político a sus organizaciones y militantes. La centralidad de estos supuestos o perspectivas de análisis -que no son propios de este campo y de hecho vertebran los estudios sobre el pasado reciente argentino así como la memoria sobre el periodo-, ha tenido como efecto una limitación importante en los estudios sobre la izquierda, inviabilizando la realización de indagaciones en una perspectiva de mediano plazo que puedan dar cuenta no sólo de los cortes y transformaciones que provocó la dictadura sino también de las continuidades y persistencias.

Si nos centramos en los estudios sobre la izquierda en el contexto de la última dictadura, debe mencionarse que el Partido Comunista (PC) ha sido la organización más analizada, entre otras muchas razones por los contactos entre la URSS y el régimen militar y por la misma línea partidaria así como, en otro registro, por la amplia cantidad de material documental que el partido produjo en el período, de fácil acceso y disponibilidad (incluso en un contexto donde la organización era reacia a abrir sus archivos). Sin embargo, contamos con una producción despareja: trabajos de indole periodística o escritos por ex militantes o allegados a la organización; balances o estados de la cuestión sobre la 
historia política del PC; algunos artículos que han analizado fundamentalmente la línea del partido durante la dictadura y/o las relaciones con la URSS, pero solo una investigación de largo aliento y con una amplia documentación que recorre todo el periodo dictatorial: la tesis doctoral de Natalia Casola.

Para el resto de la izquierda marxista, la bibliografia es notablemente escasa. Hay pocas historias "oficiales" de las organizaciones de la izquierda marxista $y$, menos aún, trabajos que incluyan las últimas décadas del siglo XX y los estudios académicos sobre la problemática en general se detienen a las puertas de la última dictadura militar. En suma, solo disponemos de un trabajo académico sobre el Partido Socialista de los Trabajadores en la dictadura, y unos pocos textos de militantes o ex militantes de organizaciones trotskistas y, en menor medida, maoístas. Finalmente, contamos con algunos estudios sobre el exilio de ciertos grupos, sobre algunas organizaciones "colaterales" del PC (Liga Argentina por los Derechos Humanos, Unión de Mujeres Argentinas), sobre algunas experiencias en el exterior como la participación en la revolución sandinista, sobre ciertas experiencias artístico-culturales o sobre espacios de sexualidad disidente. No hay indagaciones en profundidad de los efectos de la represión a la izquierda no armada (excepción hecha del PC y algunos relatos memorialísticos), de las relaciones entre los partidos de izquierda y los organismos de derechos humanos, de la izquierda en la coyuntura de Malvinas o las elecciones de 1983, por solo citar algunas cuestiones relevantes y de las que sabemos muy poco.

En lo que refiere al período de la transición democrática o más en general a los años 80, tampoco se ha analizado en profundidad el rol y la actuación de las fuerzas de la izquierda. En primer lugar, resulta necesario consignar que los análisis sobre la transición a la democracia en la Argentina estuvieron en gran parte construidos sobre perspectivas que privilegiaron los aspectos institucionales y políticos (lo que Waldo Ansaldi denominó "reduccionismo politicista"). Uno de sus principales resultados fue la atención dispensada hacia algunos actores y elementos presentes en el recambio institucional (v.g. el derrumbe de las Fuerzas Armadas, la actuación de los partidos políticos burgueses, los pactos o las negociaciones establecidas entre las cúpulas partidarias y militares) determinando que pasaran a segundo plano, se los considerara negativamente o, incluso, se invisibilizaran otros: la movilización social o la protesta popular, el movimiento obrero y sindical o las fuerzas de la izquierda. Por su parte, y como se ha dicho, el análisis de las relaciones entre partidos políticos y dictadura fue uno de los tópicos que preocuparon a los estudiosos en el curso de los años 90, tributarios de una perspectiva que cuestionaba la idea de que los partidos habian estado ausentes o que su papel había sido irrelevante durante dicho período. 
Si bien centrados en los años de la dictadura, algunos de esos trabajos avanzaron hasta las etapas iniciales del gobierno de Alfonsín y analizaron el rol clave cumplido por los partidos mayoritarios (radicalismo, peronismo) en el proceso de transición.

No es muy diferente lo que sucede con los trabajos centrados en el período alfonsinista, preocupados por analizar un conjunto de dinámicas políticas, sociales y económicas, pero que en general omitieron cualquier referencia a los partidos de la izquierda, por lo demás minoritaria en términos políticos y electorales. Excepciones son algunos trabajos sobre el PC en los años 80 con distintos énfasis y sustento documental, el texto inédito de Luciano Alonso sobre el Partido Intransigente y algunos artículos que han explorado ciertas experiencias de la izquierda específicamente en el movimiento obrero a escala regional. En resumen, sobre la temática y el período predomina un panorama caracterizado por la escasez y la fragmentariedad de los estudios. Y si es posible coincidir con el diagnóstico que indica que todavía persisten vacancias notables en el conocimiento del período de la transición democrática, sin dudas una de ellas es lo que acaeció con la izquierda argentina.

Lo que a mi juicio caracteriza los estudios sobre la izquierda en la historia reciente argentina son desbalances notables, que enuncio en un orden de vacancia creciente: 1) menor producción de conocimiento disponible sobre las organizaciones de la izquierda no armada en relación con la izquierda armada; 2) menor densidad historiográfica sobre la izquierda en dictadura respecto de los años previos al golpe; 3) menor disponibilidad aún de estudios sobre la izquierda en la posdictadura. A ello deberiamos agregar el predominio y la amplia difusión de imágenes cristalizadas, supuestos o incluso el desconocimiento liso y llano de un conjunto de cuestiones sobre la actuación de la izquierda en el periodo.

Sólo para establecer un breve contrapunto con los estudios sobre el movimiento obrero y los trabajadores en el contexto de la dictadura y la posdictadura, es evidente que estos exhiben mayor vitalidad y desarrollos más densos y complejos que los estudios sobre la izquierda en el mismo período. Superada la polémica inmovilidad/resistencia en los años dictatoriales, se ha avanzado en estudios sobre la conflictividad laboral, la resistencia obrera a la dictadura, las actitudes sociales, la vida cotidiana, los trabajadores dentro y fuera de los lugares de trabajo, etc., si bien aún subsisten vacíos significativos en esa línea de estudios. Con todo, nada similar en su extensión, densidad y complejidad está disponible para la izquierda como objeto de indagación.

Sin embargo, a favor cuentan algunos elementos. Una de las tendencias que parecen afirmarse en el campo de la historia reciente es el retroceso o el desplazamiento de la memoria a favor de la historia o de la investigación histórica, que a mi juicio es un dato positivo. Asimismo, 
se han multiplicado las posibilidades de acceder a fuentes documentales antes inaccesibles, en archivos físicos o digitales, cuestión a la que no he hecho ninguna referencia porque hubiera tomado un tiempo considerable.

Para finalizar, me gustaría postular la necesidad de poner en diálogo los campos o subcampos (las distintas "familias" o "tribus", como decía hace poco un colega) en las que nos inscribimos: la historia reciente, la historia de la izquierda, la historia obrera, más allá de las matrices que formatean y de modo de romper con la fragmentación de los abordajes y desdibujar las fronteras, ubicar las vacancias y los problemas centrales, generar un necesario diálogo e intercambio entre quienes estamos pensando y estudiando problemas muy similares. Ello habilitaría a imaginar la construcción de una historia de la izquierda que avance más allá de las décadas centrales del siglo XX y se ponga a la par de los estudios sobre el movimiento obrero y los trabajadores, a la vez que se integre más cabalmente al campo del pasado reciente, como un objeto de estudio relevante y específico.

$* * *$

\section{Algunas notas de agenda sobre la historiografía de la clase trabajadora y las izquierdas}

\section{Hernán Camarero}

Conicet - UBA - CEHTI

hercamarero@gmail.com

Agradezco mucho la participación de Gabriela y Sergio en este panel. La idea con la que se pensó este encuentro era la de ayudar a reflexionar sobre el pasado y el presente de la historiografia referida a la clase trabajadora y las izquierdas en nuestros países. En ambas intervenciones hubo elementos valiosos en este sentido, desde sus respectivos ángulos y temáticas. En mi caso, quería retomar las cuestiones de balance y, al mismo tiempo, trazar ciertas perspectivas o posibilidades de desarrollo de nuestro campo hacia el futuro. La brevedad del tiempo y del espacio disponibles hace que todo quede como una enunciación apenas telegráfica, a modo de agenda, en la que podré concentrarme solo en algunos aspectos, dejando a muchos otros de lado.

Es posible reconocer varios puntos comunes en la estructuración de nuestras áreas de estudio en Argentina y Chile, en convivencia, claro, con otras características diferenciadas, sobre todo, por el peso de ciertas tradiciones políticas, teóricas e interpretativas, asi como en 
las temporalidades de los fenómenos. A un lado y otro de la Cordillera, y esta dimensión geográfica podemos extenderla al otro lado del Río de la Plata, en Uruguay y Brasil, contamos con una rica tradición de historiografia obrera militante, formateada en un estilo muy de la primera mitad del siglo XX, y vinculada a las identidades políticas constitutivas y luego hegemónicas del movimiento obrero. Creo que en los otros tres países mencionados la predominancia más observable en esa obra fue la impronta comunista. En Argentina hubo más diversidad pues, además de esa producción proveniente del PC, también fueron significativas las elaboraciones surgidas desde comarcas ideológicas tan variadas como las del socialismo, el anarquismo y el sindicalismo revolucionario. Siempre realizamos un señalamiento crítico de esta obra, por el evidente tono hagiográfico que la caracterizó y la limitación en su objeto de análisis, esto es, un movimiento obrero entendido en términos estrechos, de raigambre sindical y activista, sin las aperturas más obvias a una historia social que considerara al conjunto de la clase, constituida, hoy lo sabemos bien, de trabajadores y trabajadoras no sólo o no siempre militantes. Pero al mismo tiempo la reconocemos como una producción que ayudó a posteriores avances y con sus testimonios permitió mantener los hilos de continuidad de una experiencia histórica. Estas elaboraciones conocieron la impugnación, a partir de los años 50 en adelante, desde territorios distintos a las izquierdas clásicas. En la Argentina se las pretendió reemplazar por un relato mayormente originado en el amplio espacio del nacional populismo de izquierda.

La constitución de una historiografia social y política de la clase trabajadora, el movimiento obrero y las izquierdas ocurrió en el medio académico recién hacia los años 60 y 70, aunque no desenfocado o escindido de preocupaciones militantes. La disciplina histórica interactuó con otras ciencias sociales, en especial la sociología, para formular los ejes de algunas de sus discusiones. En la Argentina, por ejemplo, lo fue sobre todo para organizar el debate sobre los origenes del peronismo y el reconocimiento de sus tendencias preexistentes en el universo laboral. Pero pudo también incursionarse en otros períodos y terrenos de investigación y difusión, como puede advertirse si uno repasa la experiencia del Centro Editor de América Latina (CEAL) o la experiencia del CICSO, entre muchas otras. Creo que en Chile ganó más peso específico la consideración sobre el proceso de formación y desarrollo inicial de la clase obrera y sus partidos (intentando descifrar las caracteristicas de las tradiciones recabarrenistas), y en Uruguay la indagación se orientó sobre todo hacia la comprensión de las singularidades del desarrollo de una clase trabajadora en el marco de una sociedad más estable. Las limitaciones de una parte de esta producción en clave de historia social en la región estuvieron en el excesivo peso de un determinismo 
estructuralista, que en algunos casos desatendió un análisis específico del problema de la conciencia, la incidencia de la subjetividad política y la dimensión de la cultura.

Las dictaduras de los años 70 y 80 , desde luego, en tanto procuraron arrasar con las izquierdas y el movimiento obrero, supusieron un golpe descomunal sobre nuestro campo de estudios, tanto en Argentina como en Chile, Uruguay y Brasil, y no es casual que algunos de los principales aportes en el tema deban hallarse en ediciones fuera del subcontinente, elaborados por exiliados/as e incluso por investigadores extranjeros. Si bien no se estableció una bifurcación radical en el desarrollo historiográfico entre nuestros países, sí existieron algunas discontinuidades y matices. La mayor brevedad de la dictadura argentina (que ya desde 1982 caía en desgracia), sobre todo en comparación con el régimen chileno, permitió una reconstitución más temprana de la producción local. Pero el impacto y la "metabolización de la derrota" del proceso de luchas y de radicalización ideológico-política de los años 70 ocurrió en sentidos muy similares en todos lados. Buena parte de la generación de historiadores/ as e intelectuales que antes comulgaba con la perspectiva de una historia social marxista preocupada por el estudio de la clase trabajadora mutó tras la imposición de los regímenes dictatoriales. Al calor de las lecturas sobre la crisis terminal del marxismo y bajo el prisma de una nueva revalorización de la democracia, y no del socialismo, como horizonte de deseos y convicciones, los intereses teóricos e historiográficos cambiaron y se desplazaron en todos los países.

Desde los años 80, si bien en lo inmediato hubo avances en la historia de la clase trabajadora y el movimiento obrero, un eje preponderante del relevamiento, sobre todo en Buenos Aires, se fue situando en otros tópicos: procesos de ciudadanización política, sociabilidades barriales, situaciones aleatorias de la vida cotidiana o fenómenos capturados desde una preponderante perspectiva de historia cultural, todo lo cual encontró una línea de investigación madre en la problemática de los sectores populares en el periodo de entreguerras. Ellos no dejaron de expresar progresos y ampliaciones del conocimiento. Pero la historia de la clase obrera y la propia dinámica del conflicto social quedó ubicada en la intrascendencia, y ello comprometió al propio estudio de las izquierdas, apenas limitadas a un abordaje desde el plano de las ideas o de sus intelectuales. Hubo una amplia adaptación a estas tendencias, que acumularon prestigio, autoridad y control material de las estructuras universitarias y académicas. Fue una deriva que puede reconocerse mucho más allá de la ciudad porteña y en los otros países.

Ayer, en otra mesa, discutíamos sobre las dimensiones teóricas de la producción historiográfica referida a las izquierdas en Chile. Y se señalaba la tardanza que alli había ocurrido en la recepción de la historia 
social marxista anglosajona, por ejemplo, de la obra thompsoniana, reapropiada con más sistematicidad recién a partir de la década de los 90. En Argentina, en cambio, si bien había ingresado previamente, en los primeros años 80 , lo había hecho sobre todo para convertirse en un ariete que impugnara una historiografia de clase, y para centrarla en el análisis de experiencias de construcción de consensos, integraciones y ansias de reformas democrático-populares, y no en las formas de conflicto, de resistencia o, menos aún, de proyectos revolucionarios que operaran como elementos coadyuvantes en la constitución de los sujetos sociales y politicos.

No obstante, la historiografia sobre las izquierdas y los trabajadores pudo mantenerse y progresar en estas décadas, inicialmente con cierta fragilidad, y con desigualdades y discontinuidades. Aún a pesar del medio ambiente por momentos hostil, particularmente cuando en la década del 90 en todos nuestros países imperaron las politicas, las teorías y los discursos propios de un neoliberalismo que declaró el fin de la clase, del socialismo y de la centralidad del trabajo, con la que comulgaron ciertas tendencias posmodernas en las ciencias sociales. En cierta medida, estas visiones luego también tuvieron sus crisis. En la Argentina, todo el proceso que desembocó y se heredó del 2001 fue un elemento clave para ello. Pero ese año no fue el exclusivo punto de inflexión, y no correspondería otorgarle a un factor externo semejante trascendencia. En nuestro país, hubo investigadores/as que mantuvieron esta tradición de estudios en los 80 , a las que pronto nos sumamos otros y otras, que a veces nos sentiamos como una suerte de generación sobreviviente, transitando un circunstancial desierto. Quizás era una imagen abusiva, porque en esos años 80 y 90 también ocurrieron cosas significativas, con la publicación de algunos textos importantes y el surgimiento de revistas, de algunas redes, talleres de estudio y archivos. Éramos más de lo que pareciamos, pero estábamos más dispersos y menos asociados. Si bien hubo intentos de crear espacios basados en voluntades colectivas, quedaba pendiente su sistematización como proyecto integral y con una dinámica más ofensiva, a través de centros y políticas de investigación y editoriales con continuidad. En Uruguay entiendo que la reconfiguración de una historiografia de los trabajadores y las izquierdas fue un desafio más dificilmente tramitado tras la caída de la dictadura. En Chile, con la vuelta de los/as exiliados/as también fue reconstituyéndose un nuevo campo de estudio para la historia de las izquierdas, de creciente vigor, aunque, en ciertos sentidos, con un abordaje que en muchos casos dejaba un poco escindido el vínculo de estas expresiones políticas con la experiencia de la clase trabajadora, o recaía en una tendencia opuesta, a subsumir o subordinar a aquellas al puro plano del movimiento social. 
Precisamente, retomando este último aspecto, ocurrió en términos teóricos y disciplinarios una cierta disociación de nuestra problemática historiográfica entre Chile y Argentina. De este lado de los Andes, el empeño estuvo muchas veces centrado en sostener la vitalidad de la historia social y una perspectiva de clase, en clave renovada y no conservadora. Frente a una producción demasiado inclinada al análisis de los procesos políticos y del Estado, o en otra variante, hacia una historia intelectual y cultural que desatendía la experiencia del conflicto y con frecuencia toda dimensión de actores sociales, se nos presentaba la faena de recuperar lo mejor de las viejas y las nuevas perspectivas de la historia social, pero en vínculo estrecho con el plano de la política. Claro que no de una historia "objetivista", de sujetos sociales posibles de comprenderse en su configuración por su pura disposición o agencia sin la mediación decisiva de la conciencia y la subjetividad política. En Chile, por el contrario, lo que recordaba Sergio hace un rato, la discusión quedó planteada con una prolífica obra y una perspectiva de análisis que tendió a subestimar o directamente a anular la dimensión de la política, en función del rescate de aquella potencia de lo social, de una permanente fuerza social de bajo pueblo o sectores populares. Por eso la agenda de contestación para la reafirmación de un campo de estudios sobre la clase trabajadora y las izquierdas quedó inscripta allá bajo la consigna "hacer historia social con la politica incluida". En cambio, en nuestro país entendimos la necesidad de un empeño bifronte, recordando, por un lado, la imposibilidad de hacer una historia politica (y también cultural e intelectual) de las izquierdas "sin historia social incluida" (todavia hay que precisárselo a algunos), y al mismo tiempo, invirtiendo el énfasis, debimos reafirmar la importancia de la mediación de las subjetividades politicas como componente clave en una historia social de la clase trabajadora, en oposición a planteos "objetivistas", en algunos casos, o centrados en un "descriptivismo" thompsoniano populista.

Para evitar dicotomías falsas no sólo es necesario abogar por un diálogo fértil entre las dimensiones de la historia social y la historia política en el estudio de la clase trabajadora, el movimiento obrero y las izquierdas, concibiéndolas como planos de análisis no escindidos sino concurrentes de un proceso único y de sujetos y actores completamente interrelacionados. Todo este empeño tampoco puede ser encarado sin el concurso de una historia intelectual, cultural y de género, y a partir de un diálogo interdisciplinario, cuyos enfoques apenas deberian ser ocasionalmente disociados, y en esos casos, solo en función de recortes expositivos o de especificidad temática. Convengamos que los rasgos fuertemente empiristas de la disciplina histórica y las demandas del actual modo de producción académico, obsesionado por diseñar pro- 
yectos fragmentarios y cruelmente específicos (cultores de estudios de caso a veces irrelevantes), conspiran contra el intento de reconstrucción de tramas historiográficas más densas y articuladas.

Nos parece que una parte de la nueva historia de los trabajadores y las trabajadoras, de las izquierdas y del movimiento obrero, de la que nos sentimos más representados y de la que somos también impulsores, viene produciendo conforme a este balance. Y en los últimos diez o quince años ha aparecido una nueva generación de historiadores e historiadoras que lo asumen con más naturalidad y tratan de trabajar e incluso superar estas comprensiones. Algunos de aquellos viejos debates les parecerá, con toda justeza, irrelevantes o arcaicos, aunque también es útil saber los recorridos previos y las formas de constitución de nuestro campo. Ya surgirán, probablemente ya lo están haciendo, nuevos ejes de debate y posicionamientos.

Es claro que emergen algunas perspectivas de trabajo, que se presentan como retos impostergables. Lo discutimos en estas Jornadas, en una de las mesas que abordó específicamente la relación entre género y clase como parte esencial de nuestro proyecto historiográfico. Ya hace tiempo se llegó a un punto de inflexión incuestionable, inevitable e irreversible: no puede ni siquiera formularse hoy la posibilidad de una historia de la clase trabajadora y de las izquierdas que no cuente con una radical perspectiva de género y feminista. Hablamos de una asunción definitiva y una reorientación estratégica, que plantee el vínculo esencial entre clase y género, y que coloque en un lugar de examen protagónico la secular opresión de la mujer y de las disidencias sexuales, por parte del sistema patriarcal y heteronormativo. Todo lo cual no puede pensarse sólo en términos de clase, aunque tampoco fuera de ella. Ello exige una reactualización crítica de los conceptos de explotación, opresión, dominación, hegemonia, subalternidad, antagonismo, resistencias y lucha. Ayer se dialogó aquí sobre algunas de las actuales reformulaciones teóricas de los feminismos que no se consuelan con las anteriores dificiles relaciones entre éstos y el marxismo, y que propone seguir pensándolas, volviendo a enunciar ciertos problemas con un énfasis nuevo, como la cuestión del vínculo dinámico entre la producción y la reproducción, es decir, reformulando una teoría de la reproducción social. Ello abre curso a una batería de nuevas preguntas, instrumentos teóricos, sensibilidades y formas narrativas, y que está derivando en el intento de volver a escribir de nuevo, y esperemos que mejor, la historia de la clase trabajadora, del movimiento obrero y de las izquierdas. En la revista Archivos y desde la actividad del CEHTI fuimos avanzando en esta dirección, aun siendo conscientes de todo el inmenso camino por recorrer.

Ello no implica negar la propia centralidad del trabajo, dimensión fundamental de la experiencia de los hombres y las mujeres, la que 
volvió humana a nuestra especie, pero que desde siempre es trabajo enajenado. La subsunción del proceso de trabajo al proceso de valorización marca ya el nacimiento del fetichismo del capital, que como "cosa" parece autovalorizarse con independencia del trabajo vivo. De la resistencia a la subsunción del trabajo al capital emergió hace dos siglos la clase obrera como fuerza social. Y el movimiento obrero expresa la constitución de esta clase como movimiento social, en donde las mediaciones políticas, ideológicas y culturales son fundamentales. Por ello, el estudio de la clase obrera o, como nos gusta decir, de la clase-que-vive-del-trabajo, sigue adquiriendo una indudable relevancia histórica, sociológica y política. Estamos convencidos de que el análisis de las vicisitudes del mundo de los trabajadores y las trabajadoras y la exploración de las transformaciones del movimiento obrero, continúan teniendo una importancia crucial y es un canal decisivo para la comprensión de nuestras sociedades.

Desde hace ya un tiempo largo avanzó mucho la propuesta de una historia global del trabajo, replanteando el lugar del asalariado y la variedad de formas que adquirió el trabajo productivo, improductivo y reproductivo. Al mismo tiempo, se ha ido esbozando la necesidad de una historia transnacional de las izquierdas, que replantee los problemas desde un punto de vista más amplio, abarcador, teóricamente más riguroso y a la vez ambicioso, atento a la reconstrucción de los intercambios y flujos entre fenómenos militantes, que en ocasiones se expresó en formas corporizadas (como internacionales, partidos, redes o centros asociativos) pero que en otras oportunidades alcanzó sólo la experiencia individual o de esfuerzos más acotados. Creo que en nuestros países seguimos mostrando lentitud y atraso en incorporarnos a estas discusiones, que avanzaron más en otros continentes. Nos referimos a una dimensión de reflexión global que vaya mucho más allá del también necesario enfoque de estudio comparativo de casos.

Quizás sea adecuado comenzar con un paso mucho más modesto. Y es el de integrarnos más a escala regional y si fuera posible subcontinental. Porque eso aún no ocurre como debería. Al menos entre los países más próximos, donde las problemáticas y los marcos suelen ser comunes aún en las diferencias. Y donde, además, operaron vínculos concretos entre nuestros países en los mismos procesos históricos: viajes, redes, organismos, tránsitos militantes. El solo hecho de desbordar el caso nacional nos hace un poco más lúcidos, pues pone en otra perspectiva y escala nuestros asuntos. Por eso son importantes los encuentros como éstos que estamos teniendo. Y tratamos de aprovechar cada iniciativa o proyecto de colaboración entre y con compañeros/as de Chile, Uruguay, Brasil o Bolivia, por ejemplo, por nombrar algunos de los vínculos más frecuentes. Debemos persistir en la tarea, proyectar publicaciones 
y seminarios de elaboración y estudio intensivos, y pensar en redes o nodos de articulación más firmes. Es lo que procuramos contribuir con la iniciativa del CEHTI. Como decía ayer en otra mesa, todavía veo mucho esfuerzo individual y disperso en Chile (donde la producción ya es inmensa y de gran calidad) y creo que también en Uruguay, en donde nos conectamos con lo que son esfuerzos más bien personales, no con proyectos más compactos. Con Brasil, donde el panorama es un poco distinto, nos falta lograr mayor intercambio.

Antes, o al mismo tiempo, que nos trazamos el objetivo de fortalecer esta perspectiva transnacional, al menos en escala latinoamericana, debemos asegurar ya definitivamente la construcción de un programa que se configure en una perspectiva no porteñocéntrica del mundo de los trabajadores/as y de las izquierdas. Que sin negarle su trascendencia, considere al caso de Buenos Aires como uno dentro de un entramado nacional más vasto y diverso. Y que identifique esa heterogeneidad como una cuestión empírica, conceptual, histórica y metodológica compleja, no sencilla de resolver con el amontonamiento de un par de casos regionales.

Asimismo, se impone romper la dependencia de ciertos ejes y prioridades temporales en la indagación, evitando la concentración en temas, preguntas y períodos recurrentes de tratamiento. Algo de ello se debatió también en nuestras Jornadas, en una mesa sobre historiografia chilena y argentina. Nos preguntábamos si podia reconocerse desde hace mucho tiempo algunos problemas centrales que habian organizado una parte importante de la producción y de las preguntas. En el caso de la Argentina, lo era en torno al peronismo: el significado de su aparición y de su impacto para la izquierda y la clase obrera, lo cual permitiria explicar procesos previos y tendencias posteriores, incluso hasta la actualidad. No sólo se ha escrito mucha historia de la izquierda y de los trabajadores sobre la base de lo que el peronismo expresó a partir del 17 de octubre, sino que incluso muchas de las indagaciones sobre las décadas anteriores se organizaron teniendo en cuenta y para explicar ese desenlace de 1945. Y quizás otro de los problemas articuladores en los últimos tiempos fue el del balance del ascenso revolucionario de los años 70: es decir, la relación entre la izquierda y la revolución, como proyecto, como programa, como método. En el caso de Chile, conjeturábamos si no había sido la experiencia de la Unidad Popular, como punto de llegada que condensaba tendencias previas de la izquierda y que conducía a los interrogantes acerca del porqué de su derrota. Muchos de estos análisis dieron lugar a una suerte de historiografia del fracaso anunciado.

Reconocer una preponderancia a estas problemáticas no significa necesariamente que haya que aceptarlas como tópicos casi exclusivos, pues ello no haría más que limitar la imaginación historiográfica, esta- 
bleciendo una serialidad en los ejes de discusión e incluso acotando el tiempo histórico bajo análisis. Hacia atrás, dificultando una producción más estructurada y profusa sobre los largos períodos formativos y de primer desarrollo de la clase obrera y las izquierdas en nuestros países, aun cuando ya contemos con valiosos aportes. Hacia adelante, el problema es obvio: tras la constelación de trabajos sobre la lucha armada y el ascenso setentista en la Argentina o sobre la UP en Chile, la historia de las izquierdas y los trabajadores de las etapas siguientes siguen siendo muy escasos, si bien contamos con algunos avances significativos, sobre los cuales aquí ha expuesto Gabriela.

Todo esto también nos conduce a la necesidad de seguir afrontando el desafio de encontrar la singularidad de las izquierdas: como cultura, como identidad y como tradición política, tanto en escala local como latinoamericana y mundial. Identificando sus rasgos distinguibles y relativamente homogéneos, pero también interpretando la heterogeneidad que la recorrió desde sus comienzos, conscientes de que es una categoría amplia y de contornos a veces imprecisos. Ello implica capturar su riqueza y variedad a lo largo de la historia, en la que se presentan una gran cantidad de elementos de análisis: ideologias, programas, estrategias y tácticas, discursos, polémicas, formas organizativas, modalidades de intervención, prácticas socio-culturales, influencias y liderazgos politicos e intelectuales. La historia de los partidos y corrientes políticas es sólo una de sus expresiones.

Nos interesa desarrollar estas perspectivas, a partir de los balances antes trazados. Tratamos de contribuir al desarrollo de estas líneas de investigación desde hace varios años. Y a partir de 2012 con la edición de la revista Archivos de historia del movimiento obrero y la izquierda, su Colección de libros, la puesta en funcionamiento del Centro de Estudios Históricos de los Trabajadores y las Izquierdas (CEHTI) y la realización de un número importante de actividades, como talleres, cursos, conferencias, mesas debate y estas mismas Jornadas. No hace falta más que ver la enorme cantidad de temas abordados durante estas experiencias para entender la vastedad y diversidad con las que queremos pensar nuestros objetos de estudio, independientemente de que los resultados sean más o menos logrados. Lo asumimos como expresión de un emprendimiento colectivo, que aúna voluntades múltiples y se basa en un compromiso activo. Un proyecto que tiene dimensiones historiográficas, teóricas y culturales, y que aspira a construir un mejor conocimiento, con el fin de contribuir a la lucha emancipatoria de los trabajadores y las trabajadoras, y de las izquierdas. 